\title{
Modeling maternal mortality in Bangladesh: the role of misoprostol in postpartum hemorrhage prevention
}

\author{
Ndola Prata ${ }^{1 *}$, Suzanne Bell ${ }^{2}$ and Md Abdul Quaiyum ${ }^{3}$
}

\begin{abstract}
Background: Bangladesh is one of the few countries that may actually achieve the fifth Millennium Development Goal (MDG) in time, despite skilled birth attendance remaining low. The purpose of this paper is to examine the potential role misoprostol can play in the decline of maternal deaths attributed to postpartum hemorrhage (PPH) in Bangladesh.
\end{abstract}

Methods: Using data from a misoprostol and blood loss measurement tool feasibility study in Bangladesh, observed cause specific maternal mortality ratios (MMRs) were estimated and contrasted with expected ratios using estimates from the Bangladesh Maternal Mortality Survey (BMMS) data. Using Crystal Ball 7 we employ Monte Carlo simulation techniques to estimate maternal deaths in four scenarios, each with different levels of misoprostol coverage. These scenarios include project level misoprostol coverage (69\%), no (0\%), low (40\%), and high (80\%) misoprostol coverage. Data on receipt of clean delivery kit, use of misoprostol, experience of PPH, and cause of death were used in model assumptions.

Results: Using project level misoprostol coverage (69\%), the mean number of PPH deaths expected was 40 (standard deviation $=8.01$ ) per 100,000 live births. Assuming no misoprostol coverage $(0 \%)$, the mean number of PPH deaths expected was 51 (standard deviation $=9.30$ ) per 100,000 live births. For low misoprostol coverage $(40 \%)$, the mean number of PPH deaths expected was 45 (standard deviation = 8.26) per 100,000 live births, and for high misoprostol coverage $(80 \%)$, the mean number of PPH deaths expected was 38 (standard deviation $=7.04$ ) per 100,000 live births.

Conclusion: This theoretical exercise hypothesizes that prophylactic use of misoprostol at home births may contribute to a reduction in the risk of death due to PPH, in addition to reducing the incidence of $\mathrm{PPH}$. If findings from this modeling exercise are accurate and uterotonics can prevent maternal death, misoprostol could be the tool countries need to further reduce maternal mortality at home births.

Keywords: Traditional birth attendant, Bangladesh, Postpartum hemorrhage, Maternal mortality, Misoprostol, Delivery mat, Monte Carlo

\footnotetext{
* Correspondence: ndola@berkeley.edu

${ }^{1}$ Bixby Center for Population, Health and Sustainability, School of Public Health, University of California at Berkeley, 229 University Hall, UC Berkeley, Berkeley, CA 94720-7360, USA

Full list of author information is available at the end of the article
} 


\section{Background}

Maternal mortality remains a major challenge in many settings with more than $99 \%$ of global maternal deaths still occurring in low-resource countries $[1,2]$. The lifetime risk of a woman dying in pregnancy or within 42 days of its termination is approximately 1 in 150 in developing countries and 1 in 38,000 in developed countries [3]. The fifth Millennium Development Goal (MDG) strove to address the high levels of maternal mortality throughout the world by calling for a reduction in the maternal mortality ratio (MMR) by three-quarters from 1990 to 2015 [4]. The international maternal health community's strategy to achieve this goal has primarily focused on increasing access to skilled birth attendants (SBAs) and emergency obstetric care (EmOC), but women delivering outside of health facilities have largely not benefited from these efforts [5].

Nearly half of all births worldwide (46\%) still occur outside of an institutional setting, attended by a traditional birth attendant (TBA), a relative, or no one $[6,7]$. Part of the reason that more deliveries are not attended by an SBA is the fact that many settings with high MMRs have low ratios of SBAs to women and progress in this regard has remained slow [8]. TBAs that attend these births typically do not have appropriate technologies to manage or treat complications, which explains many studies' findings that TBA trainings are not effective at improving maternal survival [9]. Despite these discouraging findings, research has shown that approximately $80 \%$ of maternal deaths are due to avoidable causes, among which hemorrhage is a leading cause $[10,11]$. Hemorrhage is estimated to be responsible for approximately $35 \%$ of maternal deaths in developing countries, although this varies widely across regions/ countries [12,13]. Postpartum hemorrhage (PPH), blood loss of $500 \mathrm{ml}$ or more, is responsible for the majority of the maternal deaths due to hemorrhage [14]. PPH poses a significant public health challenge in low-resource settings because of its low predictability [15] and the speed at which it kills; without intervention, $88 \%$ of women who die of postpartum hemorrhage die within four hours of delivery [16].

Misoprostol is a generic, low cost, heat-stable uterotonic that can be orally administered in tablet form for the prevention of $\mathrm{PPH}$. Operations research has demonstrated the safety, feasibility, and acceptability of low-level providers, or women themselves, administering misoprostol for $\mathrm{PPH}$ prevention during home deliveries in lowresource settings [17-23]. In addition, two randomized controlled trials (RCTs) evaluated the use of 600 micrograms of misoprostol compared to a placebo to prevent $\mathrm{PPH}$ in home births [24,25]. In rural India, Derman et al. demonstrated a statistically significant $47 \%$ reduction in the relative risk of $\mathrm{PPH}(\mathrm{RR}=0.53,95 \% \mathrm{CI} 0.39-0.74)$ [24].
Mobeen et al. illustrated that TBAs using misoprostol at home births in Pakistan could reduce the relative risk of $\mathrm{PPH}$ by $24 \%$ ( $\mathrm{RR}=0.76,95 \%$ CI $0.59-0.97)$ [25]. Based on a review of existing evidence, the World Health Organization (WHO) added misoprostol to the Essential Medicines List for the prevention of PPH in 2011 and now supports non-skilled birth attendant administration of misoprostol at home deliveries [26,27]. Incorporating misoprostol at home deliveries has the potential to avert PPH attributable maternal deaths at the community level where most women in low-resource settings give birth.

Bangladesh is one of the few countries that may actually achieve the fifth MDG in time, despite SBA attendance remaining low. Recent estimates put the MMR at 194 maternal deaths per 100,000 live births, which is impressive given that approximately $71 \%$ of births take place at home, of which only $4.3 \%$ are attended by a skilled provider [28]. Estimates show that $31 \%$ of maternal mortality is attributable to hemorrhage in this context, highlighting the need for community-based interventions like misoprostol to reduce preventable maternal deaths [29].

The purpose of this paper is to examine the potential role misoprostol can play in the decline of maternal deaths attributed to PPH at home births in Bangladesh. This study uses empirical data from a $\mathrm{PPH}$ prevention program and findings from previously published RCTs to model the number of PPH deaths that would result from four different scenarios of misoprostol coverage. Scenario 1 represents the project level coverage of $69 \%$; scenario 2,3 , and 4 hypothetically represent no coverage $(0 \%)$, low coverage (40\%), and high coverage $(80 \%)$, respectively.

\section{Study context}

Operations research to evaluate the feasibility and acceptability of scaling-up community-based use of misoprostol and a postpartum blood loss measurement tool was conducted in six districts of the Rangpur Division in Bangladesh from May 2009 through September 2010. The study was a collaboration between a local nongovernmental organization, Rangpur Dinajpur Rural Services (RDRS), the International Centre for Diarrheal Disease Research, Bangladesh (icddr,b) in Dhaka, the University of California, Berkeley Bixby Center for Population, Health, and Sustainability, and Venture Strategies Innovations. A total of 696 RDRS field staff, including 585 RDRS TBAs, received a two day training on misoprostol (function, dosage, timing of administration, side effects and their management, etc.) and use of the blood measurement tool, which was designed to absorb $500 \mathrm{~mL}$ of blood after delivery of the baby and be a visual cue to indicate the onset of $\mathrm{PPH}$ when the mat was full. The training also covered identifying high-risk 
pregnancies, danger signs in pregnancy, referral procedures, stages of labor, newborn resuscitation, maternal infection, and use of the clean delivery kits. The misoprostol and blood measurement tool were added to RDRS's existing clean delivery kit (CDK) at no extra charge and were distributed to clients registered with RDRS during antenatal care (ANC), or at the time of delivery by a TBA.

A total of 118,500 women enrolled in the study, of which 77,337 delivered during the project monitoring period. Of those, 67,611 (87\%) delivered at home. Verbal autopsies for all maternal deaths that occurred in the study areas during the project period were conducted. Ethical permission for the study was granted by the University of California, Berkeley (CPHS \# 2010-01-619). Additional information on the study can be found in the final report [30]. Study results on training TBAs to use misoprostol and the blood loss measurement tool in home births in Bangladesh have been published elsewhere [31].

\section{Methods}

Cause specific maternal mortality data used in this analysis came from verbal autopsies conducted in the project described above. Verbal autopsy interviews were conducted with persons who were most familiar with the specifics surrounding the maternal death using an adapted version of the tool available from the WHO [for more recent version, see: [32]]. Each verbal autopsy questionnaire was independently reviewed by two physicians in order to determine an immediate cause of maternal death using the
International Classification of Disease (ICD) 10 [33]. Final cause of death categories used include the main obstetric or direct causes of maternal death and a group of indirect causes. Cause of death categories used in this study differ from those in the study's final report because researchers combined cause of death categories to better reflect the Bangladesh Maternal Mortality Survey (BMMS) categorization $[29,30]$. Observed cause specific maternal mortality ratios are estimated and contrasted with expected ratios using estimates from the BMMS data [29].

For model building, we use project data on CDK coverage and misoprostol utilization from ANC cards and cause of death data from the verbal autopsies to categorize women (Figure 1). Coverage data includes the percentage of women who received the CDK, and misoprostol utilization is the percent of those who received the CDK who used the misoprostol (Table 1). To estimate the effectiveness of misoprostol in reducing $\mathrm{PPH}$ we use data from two RCTs where misoprostol was shown to reduce PPH by $24 \%$ to $47 \%$ when administered at home deliveries by lay providers (Mobeen, $\mathrm{RR}=0.76$, 95\% CI 0.59-0.97; Derman, RR $=0.53$, 95\% CI 0.39-0.74) $[24,25]$. In these RCTs, $17 \%$ and $6 \%$ of women experienced PPH if they took misoprostol, compared to $22 \%$ and $12 \%$ if they did not $[24,25]$. Reviews of RCTs comparing misoprostol to a placebo, although not necessarily at the community level or involving lay healthcare workers, have found risk ratios within this range, but not all findings have been significant [34-36]. The intervention did incorporate an absorbent delivery mat to visually estimate blood loss, but the delivery mat was not always utilized (68\% of

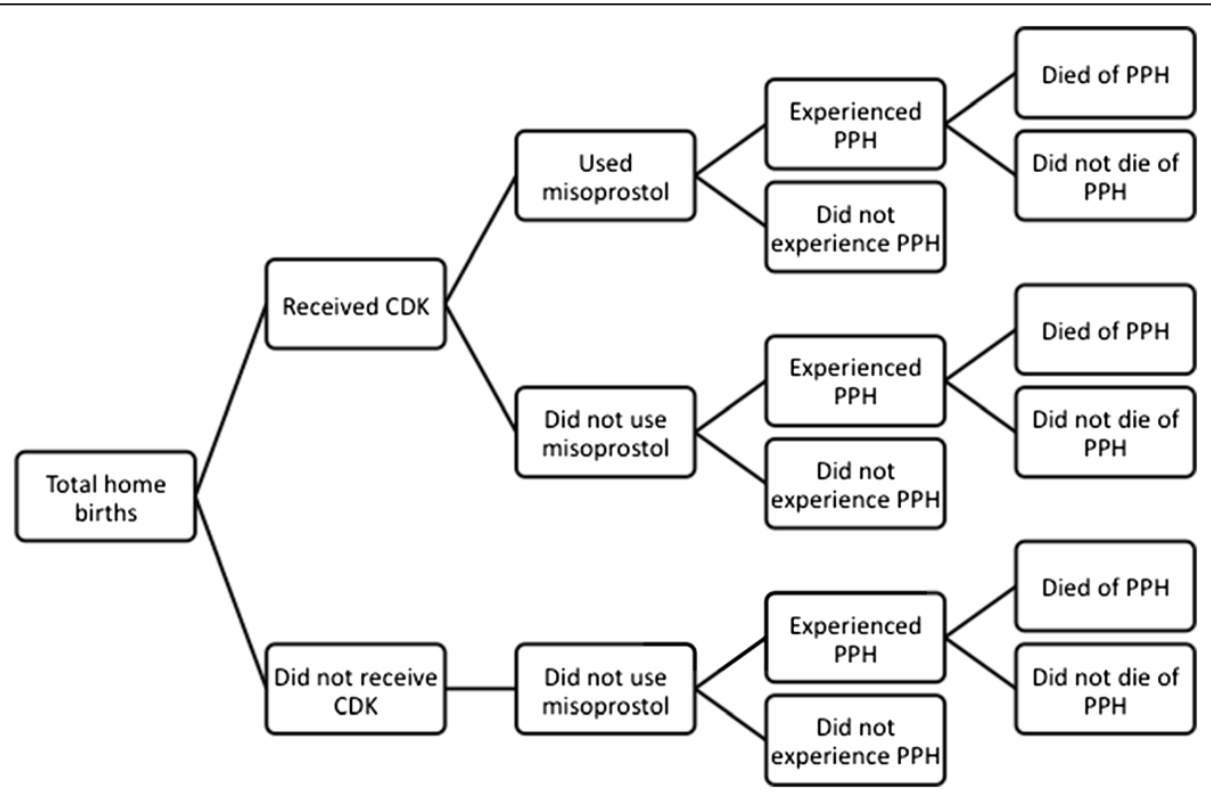

Figure 1 Flow chart of categorization of women who delivered at home by receipt of CDK, use of misoprostol, experience of PPH, and death due to PPH. 
Table 1 Assumptions in Monte Carlo modeling scenarios

\begin{tabular}{|c|c|c|c|c|c|}
\hline & \multicolumn{3}{|c|}{$\%$} & \multirow[b]{2}{*}{ Distribution } & \multirow[b]{2}{*}{ Source of assumption } \\
\hline & Minimum & Likeliest & Maximum & & \\
\hline \multicolumn{6}{|l|}{ Assumptions used in all scenarios } \\
\hline$\%$ used misoprostol had PPH & 6 & 12 & 17 & Triangle & RCTs \\
\hline$\%$ used misoprostol died of PPH & 0.2 & 0.3 & 0.4 & Triangle & Project data \\
\hline$\%$ did not use misoprostol had PPH & 12 & 17 & 22 & Triangle & RCTs \\
\hline$\%$ did not use misodied of PPH & 0.2 & 0.3 & 0.4 & Triangle & Project data \\
\hline \multicolumn{6}{|l|}{ Scenario specific assumptions } \\
\hline \multicolumn{6}{|l|}{ Scenario 1: Project data } \\
\hline$\%$ received $C D K s$ & 49 & 69 & 89 & Triangle & Project data \\
\hline$\%$ received CDK used miso & 80 & 94 & 100 & Triangle & Project data \\
\hline$\%$ did not use miso & 0 & 6 & 20 & Triangle & Project data \\
\hline \multicolumn{6}{|l|}{ Scenario 2: No misoprostol coverage } \\
\hline$\%$ received CDKs & 0 & 0 & 0 & Uniform & Set level \\
\hline$\%$ received CDK used miso & 0 & 0 & 0 & Uniform & Set level \\
\hline$\%$ did not use miso & 100 & 100 & 100 & Uniform & Set level \\
\hline \multicolumn{6}{|l|}{ Scenario 3: Low misoprostol coverage } \\
\hline$\%$ received CDKs & 20 & 40 & 60 & Triangle & Set level \\
\hline$\%$ received CDK used miso & 80 & 94 & 100 & Triangle & Project data \\
\hline$\%$ did not use miso & 0 & 6 & 20 & Triangle & Project data \\
\hline \multicolumn{6}{|l|}{ Scenario 4: High misoprostol coverage } \\
\hline$\%$ received $C D K s$ & 60 & 80 & 100 & Triangle & Set level \\
\hline$\%$ received CDK used miso & 80 & 94 & 100 & Triangle & Project data \\
\hline$\%$ did not use miso & 0 & 6 & 20 & Triangle & Project data \\
\hline
\end{tabular}

home births used the mat), nor were data collected on whether the mat was filled. Women self-reported whether they thought they experienced PPH at a postnatal appointment. If they used the mat, $\mathrm{PPH}$ was reported based on visual estimation resulting from the mat being soiled. However, in the case of a maternal death, someone involved in the delivery reported whether he/she thought the woman experienced PPH. We believe that blood loss estimation to establish PPH was more accurately measured in the RCTs, thus we used the prevalence of PPH among those who did and did not take misoprostol from previous RCTs in our modeling assumptions. Mortality data according to whether or not the woman had used misoprostol and died of PPH was taken from the verbal autopsy reports from the project data (Table 1).

We employed Monte Carlo modeling techniques using Crystal Ball 7, a stochastic modeling supplement for Excel [37]. Monte Carlo simulations are computational algorithms that utilize repeated random sampling by running simulations many times as a way of estimating probabilities. Assumption parameters are set for all variables included in the simulation, which determine the likely range of possibilities. Data on receipt of CDK, use of misoprostol, experience of $\mathrm{PPH}$, and cause of death were used to estimate parameters for the model. Most assumptions were assigned a triangle distribution, where the likeliest value in the distribution was drawn from the empirical evidence in our study or the literature, with an associated minimum and maximum value (Table 1).

Our modeling began with a hypothetical population of 100,000 singleton live births from Bangladeshi women, all of whom delivered at home. As seen in Figure 1, this population was divided into those who received a CDK and those who did not, and then those who used misoprostol and those who did not. We divided these groups into those who experienced $\mathrm{PPH}$ and those who did not. Lastly, we divided those who experienced $\mathrm{PPH}$ into those who died from $\mathrm{PPH}$ and those who did not. Thus our main outcome in the model was the total number of $\mathrm{PPH}$ related deaths. The percentages in Table 1 were used in the Monte Carlo simulation to calculate the likely probability that a woman would be in each of these categories along the "decision tree" presented in Figure 1, and ultimately, the range of probabilities that she would die of postpartum hemorrhage.

We influenced the coverage of misoprostol to create a series of scenarios, each of which was run 50,000 times. In scenario 1 , the coverage assumption was set using the 
data from the study (69\%); in scenario 2 we set the misoprostol coverage at $0 \%$; in scenario 3 we set the misoprostol coverage low at $40 \%$; and in scenario 4 we set the misoprostol coverage high at $80 \%$. We also calculated overall MMRs and the associated number of maternal deaths country-wide for each scenario, keeping all other cause specific maternal mortality ratios the same using BMMS data. We wanted to generate overall MMR estimates that incorporated scenario specific $\mathrm{PPH}$ MMRs and were generalizable to the entire country but there was evidence of significant differences between project and BMMS cause specific MMRs, thus we used BMMS cause specific MMRs. We used the most recent Bangladesh estimate for the total number of annual births to calculate the total number of maternal deaths in each of the four scenarios [38]. Lastly, we conducted a perturbation of estimates for each scenario to investigate the robustness of the estimates to changes in underlying assumptions.

\section{Results}

Overall, 117 women died during the study period, 54 (46\%) of whom died of PPH or bleeding related causes (Table 2). Among women who delivered at home during the study period $(67,611), 69 \%$ received the CDK; among those, 94\% used the misoprostol. Among this subpopulation of home deliveries that was used to inform the Monte Carlo simulation assumptions, 34 women died of PPH; 17 who took misoprostol, 16 who did not, and 1 whose misoprostol usage is unknown (Table 2).
Table 2 provides additional information on the cause of death, timing of death, place of delivery, and attendant at delivery among all maternal deaths in the study.

Based on the number of maternal deaths, we calculated overall and cause specific MMRs for the project and compared these to the expected MMRs based on the BMMS data (Table 3). The project estimated $\mathrm{PPH}$ specific MMR was 71.9 deaths per 100,000 live births whereas the BMMS PPH [combined with antepartum hemorrhage (APH)] cause specific MMR was 60.2 deaths per 100,000 live births. This difference was not statistically significant, though some of the cause specific MMRs were statistically significantly different. These include obstructed labor, other direct causes, and indirect causes. These differences are likely due to differences in the categorization of maternal deaths. We were unable to compare cause specific MMRs for APH and ruptured uterus because these cause of death categories were not used in the BMMS report.

Table 4 contains results from the four scenarios modeled using Monte Carlo simulation. We used project level data along with results from RCTs investigating the efficacy of misoprostol for $\mathrm{PPH}$ prevention at home births to inform the assumptions for the model. Using project level misoprostol coverage (69\%), the mean number of PPH deaths expected was 40 (standard deviation $=8.01$ ) per 100,000 live births. Assuming no misoprostol coverage $(0 \%)$, the mean number of $\mathrm{PPH}$ deaths expected was 51 (standard deviation $=9.30$ ) per 100,000 live births. For low misoprostol coverage (40\%), the

Table 2 Attributed cause of death, timing of death, use of misoprostol, place of delivery, and provider at delivery from verbal autopsy data from operations research in Bangladesh assessing the feasibility and acceptability of communitybased use of misoprostol and a postpartum hemorrhage blood loss measurement tool $(\mathrm{N}=117)$

\begin{tabular}{|c|c|c|c|c|c|c|c|c|c|c|}
\hline \multirow{2}{*}{ Cause of death } & \multirow{2}{*}{$\begin{array}{c}\text { Number } \\
\text { of } \\
\text { maternal } \\
\text { deaths }\end{array}$} & \multirow{2}{*}{$\begin{array}{c}\% \\
\text { distribution } \\
\text { by cause }\end{array}$} & \multicolumn{3}{|c|}{ Timing of death ${ }^{1}$} & \multirow{2}{*}{$\begin{array}{c}\text { Took } \\
\text { misoprostol }\end{array}$} & \multicolumn{2}{|c|}{$\begin{array}{l}\text { Place of } \\
\text { delivery }^{2}\end{array}$} & \multicolumn{2}{|c|}{ Attendant at delivery } \\
\hline & & & $\begin{array}{c}\text { Before } \\
\text { delivery }\end{array}$ & $\begin{array}{l}\text { During } \\
\text { delivery }\end{array}$ & $\begin{array}{c}\text { After } \\
\text { delivery }\end{array}$ & & Home & Facility & $\begin{array}{c}\text { Skilled } \\
\text { attendant }^{3}\end{array}$ & $\begin{array}{l}\text { Unskilled } \\
\text { attendant }^{4}\end{array}$ \\
\hline $\begin{array}{l}\text { Direct obstetric } \\
\text { causes }\end{array}$ & 110 & 94.0 & 24 & 17 & 67 & 27 & 44 & 34 & 37 & 67 \\
\hline $\begin{array}{l}\mathrm{PPH} \text { and bleeding } \\
\text { related }\end{array}$ & 54 & 46.2 & 4 & 7 & 42 & 17 & 34 & 15 & 19 & 31 \\
\hline $\begin{array}{l}\text { Antepartum } \\
\text { hemorrhage (APH) }\end{array}$ & 5 & 4.3 & 1 & 3 & 1 & 1 & 0 & 2 & 1 & 4 \\
\hline Eclampsia & 27 & 23.1 & 11 & 3 & 13 & 3 & 4 & 12 & 11 & 14 \\
\hline Obstructed labor & 2 & 1.7 & 0 & 2 & 0 & 0 & 0 & 0 & 0 & 2 \\
\hline Ruptured uterus & 2 & 1.7 & 1 & 0 & 1 & 1 & 1 & 0 & 0 & 2 \\
\hline Other direct causes & 20 & 17.1 & 7 & 2 & 10 & 5 & 5 & 5 & 6 & 14 \\
\hline Indirect causes & 7 & 6.0 & 3 & 0 & 4 & 0 & 3 & 1 & 1 & 6 \\
\hline Total & 117 & 100.0 & 27 & 17 & 71 & 27 & 47 & 35 & 38 & 73 \\
\hline
\end{tabular}

${ }^{1}$ Two women are missing information on timing of death, one who died of PPH and onewho died of other direct causes.

${ }^{2}$ Options were: home, upazilla health complex, upazilla health and family welfare center, private hospital/clinic, government hospital, maternal and child welfare center, in between hospital and home, other, and not applicable. "Facility" is all categories except home, between hospital and home, other, and not applicable. ${ }^{3}$ Skilled attendant is doctor or nurse/midwife.

${ }^{4}$ Unskilled includes RDRS TBA, untrained TBA, relative, village doctor, self, and other. 
Table 3 Observed and expected cause specific maternal mortality ratios

\begin{tabular}{|c|c|c|c|c|c|}
\hline \multirow[b]{2}{*}{ Cause of death } & \multirow{2}{*}{$\begin{array}{c}\text { Number } \\
\text { of } \\
\text { maternal } \\
\text { deaths }\end{array}$} & \multicolumn{3}{|c|}{ Deaths $/ 100,000$ live births } & \multirow[b]{2}{*}{ p-value } \\
\hline & & Project estimated MMR & Expected MMR (based on BMMS) ${ }^{1}$ & Difference & \\
\hline PPH and bleeding related ${ }^{2}$ & 54 & 71.9 & 60.2 & 11.73 & 0.309 \\
\hline Antepartum hemorrhage (APH) & 5 & 6.7 & $\mathrm{~N} / \mathrm{A}$ & N/A & N/A \\
\hline Eclampsia & 27 & 36.0 & 38.6 & -2.63 & 0.763 \\
\hline Obstructed labor & 2 & 2.7 & 12.5 & -9.84 & 0.012 \\
\hline Ruptured uterus & 2 & 2.7 & N/A & N/A & N/A \\
\hline Other direct causes & 20 & 26.6 & 11.4 & 15.2 & 0.014 \\
\hline Indirect causes & 7 & 9.3 & 68.2 & -58.9 & $<0.001$ \\
\hline Total & 117 & 156 & 194 & -38 & 0.042 \\
\hline
\end{tabular}

${ }^{1}$ Also had category "undetermined", MMR=2.3.

${ }^{2}$ Hemorrhage (PPH and APH) for BMMS data.

mean number of PPH deaths expected was 45 (standard deviation $=8.26$ ) per 100,000 live births, and for high misoprostol coverage (80\%), the mean number of $\mathrm{PPH}$ deaths expected was 38 (standard deviation $=7.04$ ) per 100,000 live births.

Using BMMS data for all cause specific MMRs other than PPH (which total 134 per 100,000 live births) and holding these ratios constant regardless of the level of misoprostol coverage, we calculated overall MMRs for each scenario and applied these MMRs to Bangladesh's most recent estimate for the total number of annual births [38]. This allowed us to calculate the total estimated number of maternal deaths for the country (Table 4). Using the project level scenario, 5,286 maternal deaths would occur at the national level. For the no misoprostol, low misoprostol, and high misoprostol scenarios, 5,620, 5,438, and 5,225 maternal deaths would occur, respectively, at the national level. This indicates that, given the assumptions of the scenarios, an estimated 395 PPH related maternal deaths could be averted by increasing the misoprostol coverage at home births from $0 \%$ to $80 \%$ nationwide.

The results from the sensitivity analyses reveal varying levels of contribution of each component to the variance in the number of PPH maternal deaths based on the assumptions in each scenario (Figure 2). In scenario 1 (project data, 69\% coverage), "using misoprostol and having $\mathrm{PPH}$ " and "not using misoprostol" were the components that contributed the most to the variance in the number of PPH deaths, $29 \%$ and $28 \%$, respectively. In scenario 2 (no misoprostol, 0\% coverage), "not using misoprostol and dying of PPH" and "not using misoprostol and having $\mathrm{PPH}^{\prime}$ were the only factors, the former of which contributed the greatest to the variance in the number of $\mathrm{PPH}$ maternal deaths; "not using misoprostol and dying of $\mathrm{PPH}$ " contributed slightly more than half of the variance in the total number of PPH deaths. In scenario 3 (low misoprostol, 40\% coverage), "not using misoprostol and dying of $\mathrm{PPH}$ " had the highest level of contribution to the variance in the outcome (28\%), but "not using

Table 4 Mean number of PPH specific maternal deaths and associated PPH specific and overall MMRs in a hypothetical population of 100,000 Bangladeshi women who delivered live births at home across 4 scenarios modeled using Crystal Ball

\begin{tabular}{|c|c|c|c|c|c|c|c|}
\hline Scenario & $\begin{array}{l}\text { Misoprostol } \\
\text { coverage }\end{array}$ & $\begin{array}{c}\text { Mean number of PPH } \\
\text { deaths/PPH specific } \\
\text { MMR }\end{array}$ & $\begin{array}{c}\text { Range of } \\
\text { number of PPH } \\
\text { deaths }\end{array}$ & $\begin{array}{l}\text { SD of the } \\
\text { sample } \\
\text { mean }\end{array}$ & $\begin{array}{l}\text { Expected number of all } \\
\text { other maternal deaths }{ }^{1}\end{array}$ & $\begin{array}{l}\text { Overall } \\
\text { MMR }^{1}\end{array}$ & $\begin{array}{c}\text { Estimated number } \\
\text { of maternal } \\
\text { deaths }^{2}\end{array}$ \\
\hline $\begin{array}{l}\text { Project } \\
\text { level }\end{array}$ & $69 \%$ & 40 & $15-76$ & 8.01 & 134 & 174 & 5,286 \\
\hline $\begin{array}{l}\text { No } \\
\text { misoprostol }\end{array}$ & $0 \%$ & 51 & $25-85$ & 9.30 & 134 & 185 & 5,620 \\
\hline $\begin{array}{l}\text { Low } \\
\text { misoprostol }\end{array}$ & $40 \%$ & 45 & $20-83$ & 8.26 & 134 & 179 & 5,438 \\
\hline $\begin{array}{l}\text { High } \\
\text { misoprostol }\end{array}$ & $80 \%$ & 38 & $17-70$ & 7.04 & 134 & 172 & 5,225 \\
\hline
\end{tabular}

${ }^{1}$ Calculated from BMMS MMRs (overall MMR, 194; overall MMR excluding PPH specific MMR, 134) with the assumption that all other causes of death happened at the same level as BMMS.

${ }^{2}$ Based on recent estimate of $3,038,000$ annual births [38]. 


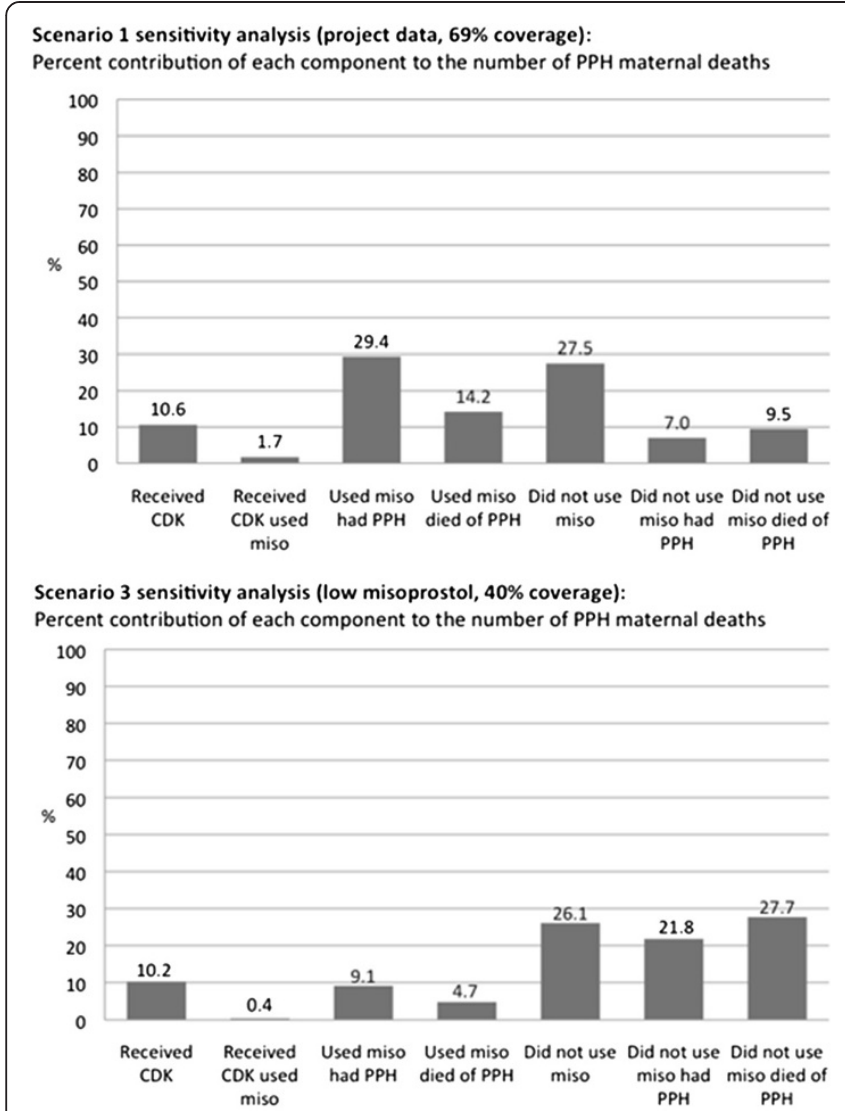

Scenario 2 sensitivity analysis (no misoprostol, $0 \%$ coverage):

Percent contribution of each component to the number of PPH maternal deaths

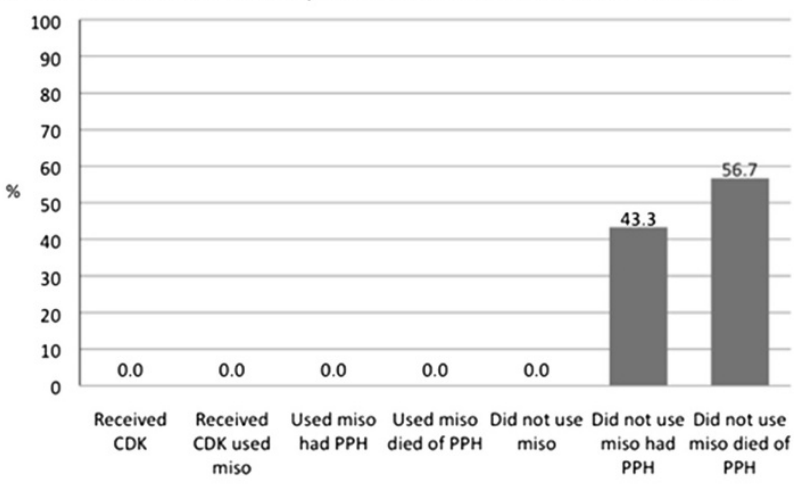

Scenario 4 sensitivity analysis (high misoprostol, $80 \%$ coverage):

Percent contribution of each component to the number of PPH maternal deaths

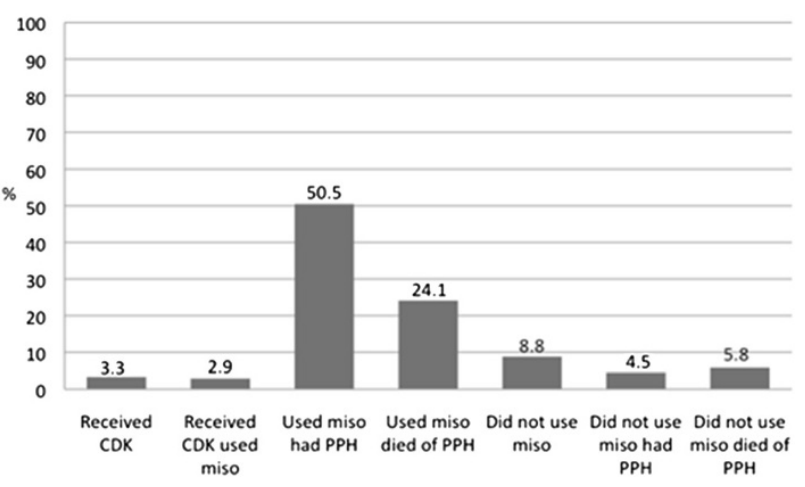

Figure 2 Results from sensitivity analyses.

misoprostol" (26\%) and "not using misoprostol and experiencing PPH" (22\%) were similarly high. In scenario 4 (high misoprostol, $80 \%$ coverage), "using misoprostol and experiencing $\mathrm{PPH}$ " was the component that contributed most to the variance in the number of $\mathrm{PPH}$ maternal deaths at $51 \%$.

\section{Discussion}

Results theorize the potential contribution misoprostol utilization at home births can have on the number of $\mathrm{PPH}$ attributable deaths and how this might affect the overall number of maternal deaths in Bangladesh if this intervention were brought to scale. This is the first modeling exercise that uses maternal mortality data from a single intervention to investigate the potential impact of prophylactic misoprostol use on $\mathrm{PPH}$ mortality. The data for this exercise come primarily from the largest misoprostol/PPH prevention intervention conducted in a low-resource setting, providing ample amounts of data from which we could formulate assumptions for the simulations.

Our findings estimate the range of $\mathrm{PPH}$ specific MMRs and total number of maternal deaths that could result from four different scenarios with varying levels of misoprostol coverage. If Bangladesh had no misoprostol coverage at home births, the estimated $\mathrm{PPH}$ specific MMR would be 51 deaths per 100,000 live births. This is in contrast to the estimated PPH specific MMR with high (80\%) misoprostol coverage, which would result in 38 deaths per 100,000 live births. If brought to scale, based on the assumptions of the simulations, this intervention has the potential to greatly reduce the total number of maternal deaths. These findings highlight how a PPH prevention intervention at home births could have a substantial impact on maternal mortality, especially in countries such as Bangladesh where a large number of births take place at home.

Despite the vast amount of data and number of women involved in the study, this project and associated analyses had several limitations. Most importantly, alternative explanations could also be used to explain the difference in mortality among those who did and did not take misoprostol. Perhaps the difference is simply due to an ecological association, whereby women who live closer to a facility are more likely to access ANC services, receive and use the misoprostol, and then more likely to access and receive life-saving care in the event of complications. Previous research found that increased 
distance to a facility was associated with increased risk of maternal mortality, but this was among women who delivered with a skilled provider; this association did not hold among those who delivered without a skilled provider [39]. All the women in the data used to calculate the assumptions for this modeling exercise delivered at home without a skilled provider, they were all enrolled in private sector ANC through RDRS (who recruited women in these rural areas door-to-door), and they could all request an RDRS TBA to be present at their delivery, who brought CDKs in the event that the woman had not already received one. Thus we feel it is unlikely that women who did not receive/use misoprostol were systematically further from a health facility than those who did. However, we acknowledge it is possible that underlying factors inherent in the woman who used the misoprostol and the mat (e.g. motivation, knowledge, etc.) also made her more likely to be transferred earlier and to receive appropriate life-saving care since the women were not randomized to use the interventions or not. The strongest evidence against this explanation is that the probability of death among those who experienced PPH was equal among those who did and did not take misoprostol $(0.3 \%)$, thus mortality was reduced via a decrease in the incidence of $\mathrm{PPH}$, not a decrease in the risk of death once one experienced $\mathrm{PPH}$.

On the whole, the PPH MMRs from the simulations are lower than that of the project data and the BMMS data. We hypothesize that it could be due to the fact that some women who were at high risk, who experienced obstetric complications early on during labor, or who had heavy bleeding immediately after labor could have been transferred to a facility and not been categorized as having delivered at home; per training instructions, immediate transfer was promoted in cases of heavy bleeding. This would likely result in an increase in the $\mathrm{PPH}$ MMR among facility deliveries and a decrease in the PPH MMR among home births than would otherwise have been expected.

The cause of death categories in the BMMS report do not align with our categories. For instance, the BMMS report combines $\mathrm{PPH}$ and APH deaths into "hemorrhage" whereas we wanted to isolate PPH attributable deaths, thus we kept PPH as a separate category. This difference, among others, resulted in the cause specific MMRs not being entirely comparable. Although not ideal, we include them nonetheless for exploration, knowing also that the BMMS MMR is for the entire country, accounting for rural and urban deliveries and home and facility deliveries; the project data contains $87 \%$ home deliveries, which is above the national average of $71 \%$, and the entire population is rural [28]. One would expect the project estimate to be higher given the great percentage of home deliveries and rural residents in comparison to the country as a whole, but our overall MMR was in fact lower. This could be due to the fact that all women were enrolled with a local NGO that provided ANC and delivery services. Despite these differences, using the BMMS MMR as the expected MMR and contrasting that with scenario specific PPH MMRs allows us to make broad yet tenuous generalizations about the total number of maternal deaths expected at a national level. Because the scenario specific $\mathrm{PPH}$ MMRs were much lower than the study or the BMMS PPH MMRs, our findings are likely conservative estimates of the total number of PPH deaths that could be averted at the national level in Bangladesh.

The use of verbal autopsy to determine cause of death is a limitation. Because of the number of women involved in the study and the fact that nearly all deliveries were conducted at home without a skilled provider, researchers had to rely on interviews with someone (often a close relative) involved in the delivery of each woman who died in the study. Given the nature of the intervention, which included an IEC campaign about the dangers of $\mathrm{PPH}$ specifically, there was a heightened awareness among women and families of the risk of $\mathrm{PPH}$, and a blood collection mat was used to assess bleeding. This could have contributed to increases in the reporting of bleeding when other symptoms or signs were ignored and not reported, resulting in differential misclassification of cause of death, with more deaths being classified by those interviewed for the verbal autopsy as a death due to excessive bleeding. This would help to explain why the study's PPH specific MMR was much higher than the BMMS estimate.

The assumption that the rate of PPH mortality is constant across the population is another limitation. The more marginalized women who do not attend ANC and who do not receive a CDK likely have a higher $\mathrm{PPH}$ mortality rate than those who do. We were unable to estimate and incorporate these potential differences in our modeling, thus the findings do not accurately capture the fact that increasing coverage may not be linearly associated with reductions in PPH mortality.

Additionally, incomplete data on one PPH maternal death resulted in the exclusion of the case because we could not categorize the death according to misoprostol use. The potential difference that would result from the correct categorization of this woman would not be substantial, thus we do not feel this significantly biased our results.

Despite these limitations, the results of this modeling exercise hypothesize the potential differences in overall maternal deaths that could result from varying levels of misoprostol coverage throughout the country. Compared to no misoprostol coverage, findings indicate that achieving $80 \%$ coverage (with $94 \%$ utilization among that $80 \%$ ) might be associated with a reduction in the overall MMR 
of 13 maternal deaths (185 to 172 ) per 100,000 live births; this is equivalent to a $7 \%$ reduction in overall maternal mortality. The $7 \%$ reduction represents about a quarter (23\%) of the $31 \%$ of total maternal mortality that is attributable to PPH in Bangladesh. The remaining $77 \%$ of $\mathrm{PPH}$ maternal mortality could require a stronger uterotonic, more uterotonics, or other interventions in order to prevent mortality among these cases. Little is known about the causes of PPH that result in mortality, thus it could be that of the $31 \%$ of maternal deaths due to $\mathrm{PPH}$ in Bangladesh, only $23 \%$ of it can be prevented by misoprostol and the remainder would require other interventions; this is less than previously thought given the assumption that most PPH is due to uterine atony, which would be responsive to uterotonics.

The overall reduction in maternal mortality from this study is actually lower than that observed in other modeling exercises [40-42]. If true, this could mean a decrease in the cost-effectiveness of this approach [40,41]. Use of misoprostol for PPH treatment is a more costeffective intervention [41], but it would require getting more women to deliver in facilities and encouraging early transfer among home births in order to treat $\mathrm{PPH}$ cases, which are difficult to predict [15]. Nonetheless, the hypothetical scenarios in this modeling exercise present the possibility that many lives could be saved in Bangladesh, and other countries, by increasing coverage of misoprostol availability among women delivering at home; a potential 7\% reduction in MMR is not an insignificant number of lives saved. Additional empirical evidence is needed to confirm the results of this modeling exercise and the incidence of PPH mortality among women who do and do not take misoprostol.

\section{Conclusion}

This theoretical exercise hypothesizes that prophylactic use of misoprostol at home births may contribute to a reduction in the risk of death due to $\mathrm{PPH}$, in addition to reducing the incidence of $\mathrm{PPH}$, if uterotonics can in fact prevent maternal death. Even after the WHO's decision to support misoprostol use for PPH prevention at home births, there have been continued opponents of misoprostol use for this purpose, claiming insufficient evidence [43]. Other researchers pooled existing study data to determine the potential impact of misoprostol on PPH mortality and found that its use neither increased nor decreased mortality or severe morbidity [44]. The findings from our modeling exercise support the case for misoprostol use at home births in low-resource settings and hypothesize the potential reductions in maternal death due to $\mathrm{PPH}$ that can be achieved with various levels of misoprostol coverage, incorporating empirical data from a large field trial. If findings from this modeling exercise correspond to the possible effect of misoprostol use on $\mathrm{PPH}$ mortality, misoprostol could be the tool that countries need in order to further reduce maternal mortality at home births.

\section{Abbreviations}

ANC: Antenatal care; BMMS: Bangladesh Maternal Mortality Survey; CDK: Clean delivery kit; EmOC: Emergency obstetric care; ICD: International Classification of Disease; icddr,b: International Centre for Diarrheal Disease Research, Bangladesh; MDG: Millennium Development Goal; MMR: Maternal mortality ratio; NGO: Non-governmental Organization; PPH: Postpartum hemorrhage; RDRS: Rangpur Dinajpur Rural Services; SBA: Skilled birth attendant; TBA: Traditional birth attendant; WHO: World Health Organization.

\section{Competing interests}

The authors declare that they have no competing interests.

\section{Authors' contributions}

NP had the idea for this manuscript and helped with the analyses and the writing. SB conducted the analyses and did much of the writing. MAQ helped with the writing and oversaw data collection in-country. All authors read and approved the final manuscript.

\section{Acknowledgements}

We would like to thank Dr. Salima Rahman for her help in facilitating the operations research through her department at RDRS. Her cooperation was invaluable. We would also like to thank all RDRS TBAs, CHWs, and managers, all of whom were integral to the success of this project, as well as the participating women and communities. And we are grateful to Venture Strategies Innovations for providing the funds necessary to incorporate misoprostol and the delivery mat into the clean delivery kits.

\section{Author details}

${ }^{1}$ Bixby Center for Population, Health and Sustainability, School of Public Health, University of California at Berkeley, 229 University Hall, UC Berkeley, Berkeley, CA 94720-7360, USA. Bixby Center for Population, Health and Sustainability, School of Public Health, University of California at Berkeley, 17 University Hall, UC Berkeley, Berkeley, CA 94720-7360, USA. ${ }^{3}$ icddr,b, Centre for Reproductive Health, GPO Box 128, Dhaka 1000, Bangladesh.

Received: 2 August 2013 Accepted: 5 February 2014 Published: 20 February 2014

\section{References}

1. Hogan MC, Foreman KJ, Naghavi M, Ahn SY, Wang M, Makela SM, Lopez AD, Lozano R, Murray CJ: Maternal mortality for 181 countries, 1980-2008: a systematic analysis of progress towards Millennium Development Goal 5. Lancet 2010, 375(9726):1609-1623.

2. WHO, UNICEF, UNFPA, The World Bank: Trends in Maternal Mortality: 1990 to 2008. Geneva: World Health Organization; 2010.

3. Maternal mortality: Fact sheet number 348. [http://www.who.int/ mediacentre/factsheets/fs348/en/index.html]

4. United Nations General Assembly: United Nations Millenium Declaration. New York: United Nations; 2000.

5. Adegoke AA, van den Broek N: Skilled birth attendance-lessons learnt. BJOG 2009, 116(Suppl 1):33-40.

6. UNICEF: The State of the World's Children 2009: Maternal and Newborn Health. New York: United Nations Children's Fund; 2008.

7. STATcompiler. http://www.measuredhs.com.

8. Prata N, Passano P, Rowen T, Bell S, Walsh J, Potts M: Where there are (Few) skilled birth attendants. J Health Popul Nutr 2011, 29(2):81-91.

9. Sibley LM, Sipe TA, Brown CM, Diallo MM, McNatt K, Habarta N: Traditional birth attendant training for improving health behaviours and pregnancy outcomes. Cochrane Database Syst Rev 2007, 3:CD005460.

10. Kilpatrick SJ, Crabtree KE, Kemp A, Geller S: Preventability of maternal deaths: comparison between Zambian and American referral hospitals. Obstet Gynecol 2002, 100(2):321-326.

11. Wessel H, Reitmaier P, Dupret A, Rocha E, Cnattingius S, Bergstrom S: Deaths among women of reproductive age in Cape Verde: causes and avoidability. Acta Obstet Gynecol Scand 1999, 78(3):225-232.

12. United Nations: The Millenium Development Goals: Report 2010. New York: United Nations; 2010. 
13. Khan KS, Wojdyla D, Say L, Gulmezoglu AM, Van Look PF: WHO analysis of causes of maternal death: a systematic review. Lancet 2006, 367(9516):1066-1074.

14. AbouZahr C: Global burden of maternal death and disability. Br Med Bull 2003, 67:1-11

15. Prata N, Hamza S, Bell S, Karasek D, Vahidnia F, Holston M: Inability to predict postpartum hemorrhage: insights from Egyptian intervention data. BMC Pregnancy Childbirth 2011, 11:97.

16. Ramanathan G, Arulkumaran S: Postpartum hemorrhage. J Obstet Gynaecol Can 2006, 28(11):967-973.

17. Prata N, Mbaruku G, Campbell M, Potts M, Vahidnia F: Controlling postpartum hemorrhage after home births in Tanzania. Int J Gynaecol Obstet 2005, 90(1):51-55.

18. Hashima EN, Nahar S, Al Mamun M, Afsana K, Byass P: Oral misoprostol for preventing postpartum haemorrhage in home births in rural Bangladesh: how effective is it? Glob Health Action 2011, 4:7017.

19. Prata N, Gessessew A, Abraha AK, Holston M, Potts M: Prevention of postpartum hemorrhage: options for home births in rural Ethiopia. Afr J Reprod Health 2009, 13(2):87-95.

20. Sanghvi H, Ansari N, Prata NJV, Gibson H, Ehsan AT, Smith JM: Prevention of postpartum hemorrhage at home birth in Afghanistan. Int J Gynaecol Obstet 2010, 108(3):276-281.

21. Rajbhandari S, Hodgins S, Sanghvi H, McPherson R, Pradhan YV, Baqui AH: Expanding uterotonic protection following childbirth through community-based distribution of misoprostol: operations research study in Nepal. Int J Gynaecol Obstet 2010, 108(3):282-288.

22. Prata N, Ejembi C, Fraser A, Shittu O, Minkler M: Community mobilization to reduce postpartum hemorrhage in home births in northern Nigeria. Soc Sci Med 2012, 74(8):1288-1296.

23. Chandhiok N, Dhillon BS, Datey S, Mathur A, Saxena NC: Oral misoprostol for prevention of postpartum hemorrhage by paramedical workers in India. Int J Gynaecol Obstet 2006, 92(2):170-175.

24. Derman RJ, Kodkany BS, Goudar SS, Geller SE, Naik VA, Bellad MB, Patted SS, Patel A, Edlavitch SA, Hartwell T, et al: Oral misoprostol in preventing postpartum haemorrhage in resource-poor communities: a randomised controlled trial. Lancet 2006, 368(9543):1248-1253.

25. Mobeen N, Durocher J, Zuberi N, Jahan N, Blum J, Wasim S, Walraven G, Hatcher J: Administration of misoprostol by trained traditional birth attendants to prevent postpartum haemorrhage in homebirths in Pakistan: a randomised placebo-controlled trial. BJOG 2011, 118(3):353-361.

26. World Health Organization (WHO): WHO recommendations for the prevention and treatment of postpartum haemorrhage. Geneva: World Health Organization (WHO); 2012.

27. World Health Organization (WHO): The Selection and Use of Essential Medicines. Geneva: World Health Organization (WHO); 2011.

28. National Institute of Population Research and Training (NIPORT), Mitra and Associates, ICF International: Bangladesh Demographic and Health Survey 2011. Dhaka, Bangladesh and Calverton, Maryland, USA: NIPORT, Mitra and Associates, and ICF International; 2013

29. National Institute of Population Research and Training (NIPORT), MEASURE Evaluation, UNC-CH, ICDDR B: Bangladesh Maternal Mortality and Health Care Survey 2010: Preliminary Results. Dhaka: NIPORT; 2011.

30. Quaiyum MA, Holston M, Bell S, Prata N: Scaling up of misoprostol for prevention of postpartum hemorrhage in 29 upazilas in Bangladesh. Berkeley: Venture Strategies Innovations; 2011.

31. Prata N, Quaiyum MA, Passano P, Bell S, Bohl DD, Hossain S, Azmi AJ, Begum M: Training traditional birth attendants to use misoprostol and an absorbent delivery mat in home births. Soc Sci Med 2012, 75(11):2021-2027.

32. World Health Organization (WHO): Verbal autopsy standards: The 2012 WHO verbal autopsy instrument, Release Candidate 1. Geneva: World Health Organization (WHO); 2012

33. World Health Organization (WHO): International statistical classification of diseases and related health problems (10th revised edition). Geneva: World Health Organization (WHO); 2008.

34. Olefile KM, Khondowe O, M'rithaa D: Misoprostol for prevention and treatment of postpartum haemorrhage: a systematic review. Curationis 2013, 36(1):E1-E10

35. Oladapo OT: Misoprostol for preventing and treating postpartum hemorrhage in the community: a closer look at the evidence. Int J Gynaecol Obstet 2012, 119(2):105-110.
36. Tunçalp Ö, Hofmeyr GJ, Gülmezoglu AM: Prostaglandins for preventing postpartum haemorrhage. Cochrane Database Syst Rev 2012, 8:CD000494.

37. Oracle Corporation: Oracle Crystal Ball 7. USA; 2008.

38. Patted SS, Goudar SS, Naik VA, Bellad MB, Edlavitch SA, Kodkany BS, Patel A, Chakraborty H, Derman RJ, Geller SE: Side effects of oral misoprostol for the prevention of postpartum hemorrhage: results of a community-based randomised controlled trial in rural India. J Maternal-fetal Neonatal Med 2009, 22(1):24-28.

39. Scott S, Chowdhury ME, Pambudi ES, Qomariyah SN, Ronsmans C: Maternal mortality, birth with a health professional and distance to obstetric care in Indonesia and Bangladesh. Trop Med Int Health 2013, 18(10):1193-1201.

40. Sutherland T, Bishai DM: Cost-effectiveness of misoprostol and prenatal iron supplementation as maternal mortality interventions in home births in rural India. Int J Gynaecol Obstet 2009, 104(3):189-193.

41. Sutherland T, Meyer C, Bishai DM, Geller S, Miller S: Community-based distribution of misoprostol for treatment or prevention of postpartum hemorrhage: cost-effectiveness, mortality, and morbidity reduction analysis. Int J Gynaecol Obstet 2010, 108(3):289-294.

42. Pagel C, Lewycka S, Colbourn T, Mwansambo C, Meguid T, Chiudzu G, Utley $M$, Costello AML: Estimation of potential effects of improved communitybased drug provision, to augment health-facility strengthening, on maternal mortality due to post-partum haemorrhage and sepsis in sub-Saharan Africa: an equity-effectiveness model. Lancet 2009, 374 (9699):1441-1448.

43. Chu CS, Brhlikova P, Pollock AM: Rethinking WHO guidance: review of evidence for misoprostol use in the prevention of postpartum haemorrhage. J R Soc Med 2012, 105(8):336-347.

44. Hofmeyr GJ, Gülmezoglu AM, Novikova N, Lawrie TA: Postpartum misoprostol for preventing maternal mortality and morbidity. Cochrane Database Syst Rev 2013, 7:CD008982.

doi:10.1186/1471-2393-14-78

Cite this article as: Prata et al:: Modeling maternal mortality in Bangladesh: the role of misoprostol in postpartum hemorrhage prevention. BMC Pregnancy and Childbirth 2014 14:78.

\section{Submit your next manuscript to BioMed Central and take full advantage of:}

- Convenient online submission

- Thorough peer review

- No space constraints or color figure charges

- Immediate publication on acceptance

- Inclusion in PubMed, CAS, Scopus and Google Scholar

- Research which is freely available for redistribution 